\title{
FDA Clinical Outcome Assessment Qualification
}

National Cancer Institute

\section{Source}

National Cancer Institute. FDA Clinical Outcome Assessment Qualification. NCI

Thesaurus. Code C142552.

FDA confirmation that a clinical outcome assessment is a reliable measure for a specific interpretation and application within the stated context of use. 